\title{
Application of Music Training on Enhancing Auscultation Ability in Nursing Undergraduates: A Pilot Study
}

\author{
Xiaofen Qin ${ }^{1,2}$, Xiuhua Wang ${ }^{1}$, Jia Guo ${ }^{1}$, Miao Wang ${ }^{3}$, Jia Chen ${ }^{2,}$ * \\ ${ }^{1}$ Xiangya School of Nursing, Central South University, Changsha, China \\ ${ }^{2}$ Hainan General Hospital, Haikou, China \\ ${ }^{3}$ School of Architecture and Art, Central South University, Changsha, China
}

Email address:

qinxiaofen@csu.edu.cn (Xiaofen Qin),653012790@qq.com (Xiuhua Wang),50992188@qq.com (Jia Guo), 1018535@qq.com (Miao Wang), hlxycjia@csu.edu.cn (Jia Chen)

${ }^{*}$ Corresponding author

\section{To cite this article:}

Xiaofen Qin, Xiuhua Wang, Jia Guo, Miao Wang, Jia Chen. Application of Music Training on Enhancing Auscultation Ability in Nursing Undergraduates: A Pilot Study. American Journal of Nursing Science. Vol. 8, No. 5, 2019, pp. 239-242. doi: 10.11648/j.ajns.20190805.16

Received: May 25, 2019; Accepted: August 12, 2019; Published: September 5, 2019

\begin{abstract}
Art is playing a more important role in nursing education as the two disciplines interconnect. Music has been used in western countries to improve the ability of medical and nursing students' clinical skills in performing physical examination. But in China, very little literature focuses on music. The aim of this research is to explore the effect of music training in improving students' auscultation ability in the course of physical examination for nursing undergraduates. Second year nursing undergrraduates $(n=125)$ were allocated to either the intervention group or the control group randomly. The control group $(n=62)$ received the traditional training, the intervention group $(n=63)$ received the traditional teaching, plus music training consisted of pitch, rhythm, timing, intensity, tenth, masking into the physical examination course. Both groups were evaluated on their ability to interpret 5 sounds ( 2 heart sounds, 2 lung sounds and 1 bowel sound) before the course and 15 sounds (6 heart sounds, 5 lung sounds, 2 bowel sounds and 1 mixed sound) after the course. The control group overall score was no significant differences compared to the intervention group which in the heart sounds, lung sounds and bowel sound before the course. After the course, the intervention group score of listening test was significant higher than control group which in the heart sounds, lung sounds and mixed sound. The results showed that the application of music training can improve the students' auscultation ability to a certain extent.
\end{abstract}

Keywords: Music Training, Auscultation Ability, Nursing Undergraduates

\section{Introduction}

Through interdisciplinary cooperation, medicine and art gradually have developed a closer relationship [1]. This interdisciplinary cooperation between medicine and art provides an innovative, participatory, and responsive method of learning for students [2,3]. For many years, the use of art in medical education has been identified by more and more scholars both at home and abroad [4], and many researches showed that the use of art could improve students' humanistic quality [5-7], enhance communication and observation skills [8-10], and promote students to open their minds of thinking [11-13]. The physical examination is the bridge between basic nursing and clinical nursing [14], it covers a wide range of knowledge that requires students not only to memorize the theoretical knowledge of health assessment signs, but also to master the corresponding evaluation skills and apply the knowledge into clinical practice [15]. Therefore, it is very important to develop effective teaching methods to help students master the course content.

Art refers to the form of visual and auditory perception, including drama, poetry, dance, music, images, and so forth [16]. With the introduction of art into medical education, Chinese researchers have made some achievements in combining art with medical classes [17], and this study aims to incorporate music training into the practice course of physical examination and evaluate the effects of applying music training on the nursing undergraduates in the physical examination. 


\section{Methods}

\subsection{Design and Sampling}

The study took place in a nursing college in Changsha, China. A Cluster randomized control method was used in this study, a total of 125 second year nursing undergraduates from four teaching classes were divided randomly into two cluster groups. Four envelopes were prepared: two contained a card labelled with "1"; the other two cards were labelled with "2" ("1" represented the intervention group and "2" represented the control group). Each student from four teaching classes selected an envelope determined whether theirs were in the control group or intervention group. There were 7 males and 55 females $(n=62)$ in intervention group and 6 males and 57 females $(n=63)$ in control group. No statistically significant differences were found in sex, age and previous music training between the two groups and detailed information for students see Table 1 .

Table 1. General Characteristics of the Students.

\begin{tabular}{|c|c|c|c|c|c|c|}
\hline Content & & Intervention group $(n=62)$ & Control group $(n=63)$ & Total & $\chi^{2}$ & $\mathbf{P}$ \\
\hline \multirow{2}{*}{ Gender } & Male & 7 & 6 & 13 & \multirow{2}{*}{0.105} & \multirow{2}{*}{0.746} \\
\hline & Female & 55 & 57 & 112 & & \\
\hline \multirow{4}{*}{ Age } & $\leq 18$ & 4 & 4 & 8 & \multirow[t]{4}{*}{0.354} & \multirow[t]{4}{*}{0.724} \\
\hline & 19 & 36 & 33 & 69 & & \\
\hline & 20 & 19 & 24 & 43 & & \\
\hline & $\geq 21$ & 3 & 2 & 5 & & \\
\hline \multirow{4}{*}{ Previous music training (year) } & none & 39 & 37 & 76 & \multirow[t]{4}{*}{0.681} & \multirow[t]{4}{*}{0.954} \\
\hline & $1 \sim 6$ & 5 & 6 & 11 & & \\
\hline & $7 \sim 10$ & 2 & 3 & 5 & & \\
\hline & $>10$ & 3 & 2 & 5 & & \\
\hline
\end{tabular}

\subsection{Interventions}

The physical examination course was started in the second grade. The control group received the traditional method consisting of oral lecturing and Case-Based Learning (CBL). The intervention group received the traditional method, and the music training. Music training was comprised by three steps: 1) learning basic musical knowledge, 2) learning musical elements (such as beat, intensity, pitch, timbre, etc.), and 3) learning masking. A professional music teacher conducted one hour of training before the clinical auscultation teaching. Two different styles of music, each containing different musical elements, were played for students. They were asked for the differences between the two musical segments and what they felt. Then, the teacher taught basic knowledge of musical elements to students and gave examples to guide students in distinguishing different musical elements. For example, after the teacher taught the mechanism of the cardiac auscultation, the professional music teacher played some segments of synthetic cardiac audio and taught students to distinguish different cardiac sounds through different musical elements. Then the teacher used similar types of cardiac auscultations to let students repeat the listening exercises to train students' auscultation skill. In actual clinical practice, auscultation is disturbed by external environment and other body sounds, so we also added external environmental interference and/or body sounds into the synthetic auscultation audio to train students' masking skill. The study was approved convened review by the IRB.

\subsection{Outcome Measures}

To evaluate the effectiveness of music training, students of two groups were given audio test of auscultation before and after the music training. We synthesized the auscultation sounds into a complete audio, each auscultation sound lasted 20 seconds, and students were given 15 seconds to write the answers. The pretest includes 2 heart sounds (normal heart sound and $\mathrm{S}_{2}$ Enhancement), 2 lung sounds (bronchial breathing sound and wheezes) and 1 bowel sound (Hyper-sonic bowel sound). The post-test included 6 heart sounds (Sinus tachycardia, gallop rhythm, systolic ejection murmur, diastolic rumble murmur, S2 enhancement and bigeminy coupled rhythm), 5 lung sounds (alveolar respiratory sound, bronchoalveolar breathing sound, bronchial breathing sound, crackles and wheezing rale), 2 bowel sounds (hyper-sonic bowel sound and hypo-active bowel sound) and 1 mixed sound (sinus bradycardia + bronchial breathing sound + environmental sound). The higher the student scored, the better auscultation ability they had.

\subsection{Data Analyses}

Data were double entered into SPSS 18.0 by two postgraduates who were not aware of the study group assignment, and described by Median, Q1 and Q3. The Wilcoxon rank sum test was used to examine differences in scores between the intervention and control group. All tests were two-sided with an alpha of 0.05 .

\section{Results}

There was no significant difference in the score of auscultation ability test between the two groups before the music training $(Z=-1.751, P=0.080)$. 
Table 2. Comparison of Scores of Audio Test of Auscultation Between the Two Groups Before the Music Training.

\begin{tabular}{lllllllll}
\hline \multirow{2}{*}{ Content } & \multicolumn{7}{l}{ Intervention group $(\mathbf{n}=\mathbf{6 2})$} & \multicolumn{2}{l}{ Control group $(\mathbf{n}=\mathbf{6 3})$} & \multirow{2}{*}{$\mathbf{Z}$} & \multirow{2}{*}{$\mathbf{P}$} \\
\cline { 2 - 7 } & Median & $\mathbf{Q 1}$ & $\mathbf{Q 3}$ & Median & $\mathbf{Q 1}$ & $\mathbf{Q 3}$ & -1.148 \\
Heart sounds & 2.00 & 2.00 & 2.25 & 2.00 & 2.00 & 2.00 & 0.251 \\
Lung sounds & 2.00 & 1.00 & 2.00 & 2.00 & 1.00 & 2.00 & -1.683 & 0.092 \\
Bowel sound & 1.00 & 0.00 & 1.00 & 1.00 & 0.00 & 1.00 & -0.164 & 0.869 \\
Total score & 4.00 & 4.00 & 5.00 & 4.00 & 4.00 & 5.00 & -1.751 & 0.080 \\
\hline
\end{tabular}

After the course, there were significant differences in the scores of heart sounds, lung sounds, mixed sound and total score between the two groups $(\mathrm{P}<0.05)$, but there was no significant difference in the scores of bowl sound $(\mathrm{P}>0.05)$.

Table 3. Comparison of Scores of Audio Test of Auscultation Between the Two Groups After the Music Training.

\begin{tabular}{|c|c|c|c|c|c|c|c|c|}
\hline \multirow{2}{*}{ Content } & \multicolumn{3}{|c|}{ Intervention group $(n=62)$} & \multicolumn{3}{|c|}{ Control group $(n=63)$} & \multirow{2}{*}{$\mathbf{Z}$} & \multirow{2}{*}{$\mathbf{P}$} \\
\hline & Median & Q1 & Q3 & Median & Q1 & Q3 & & \\
\hline Heart sounds & 5.00 & 4.00 & 5.00 & 3.00 & 3.00 & 4.00 & -4.808 & 0.000 \\
\hline Lung sounds & 3.00 & 3.00 & 4.00 & 2.00 & 1.00 & 3.00 & -4.693 & 0.000 \\
\hline Bowel sound & 2.00 & 1.00 & 2.00 & 2.00 & 1.00 & 2.00 & -0.295 & 0.768 \\
\hline Mixed sound & 1.00 & 1.00 & 2.00 & 0.00 & 0.00 & 1.00 & -0.493 & 0.000 \\
\hline Total score & 10.00 & 9.00 & 11.25 & 8.00 & 7.00 & 9.00 & -7.247 & 0.000 \\
\hline
\end{tabular}

\section{Discussion}

Auscultation is an important part of evaluating a patient's disease condition, it is also a difficult part of the course of physical examination [18]. Previously, teachers used traditional methods to train students in the ability of auscultation, explaining the mechanism and difference between the auscultation sounds of each organ. Then, the students performed the auscultation practice on models or on patients [19]. Most auscultation sounds need to be understood and judged by the students themselves, and because of the diversity and complexity of the content of the auscultation (especially the heart and lungs), many students have a poor mastery of auscultation. As a physiological or pathological sound, auscultation sounds are similar to music and its different musical elements. Because of this similarity, some foreign scholars have incorporated music appreciation into medical education. It was discovered that learning musical elements helped medical students improve their ability in distinguishing auscultation sounds [20].

Art could help students use multiple senses to learn and think deeply, it also could encourage students to express more than personal knowledge using deeper intuition [21]. Therefore, this study conducted a music appreciation and musical element learning course, helping students learn clinical auscultation sounds corresponding to musical elements, the music lecturer decomposed the difficult clinical auscultation sounds into different musical elements that helped students to analyze and distinguish the clinical auscultation sounds in relationship to the musical elements, thereby cultivating their ability to distinguish the clinical auscultation sounds.

At present, the main teaching methods commonly used in the practice course of health assessment are Case-Based Learning, scene simulation, and flipped classroom, supplemented with other teaching methods [22], with limited ways to add art into the course. This study integrated art into nursing education through the introduction of art, it not only opened up new ideas of nursing education, but it also enriched the content of the course [23]. It can create a relaxed and happy learning atmosphere, while enhancing students' interest in learning and its effectiveness. Meanwhile, students can master basic art appreciation and its elements, which has a certain effect on the development and the improvement of their overall character.

There are some limitations in this study, more evaluation measures are needed. The combination of music training and nursing education is a new attempt of cross-disciplinary. At present, there is no objective evaluation scale for the auscultation ability of nursing undergraduates. The next step will be the development of evaluation scales for the auscultation ability of nursing undergraduates, thereby enriching the evaluation indicators and resulting in much more objective evaluations.

\section{Conclusion}

The application of auditory art training in the practice course of physical examination can improve the students' auscultation skill. It also can help students master and apply the course content, while improving their comprehension and learning efficiency to a certain extent. In view of the characteristics of medical universities, we believe that music training can be further integrated with the contents of nursing courses, so that music training can play a greater role in medical education.

\section{Acknowledgements}

So much thanks for the support of Central South University and Yale-China Association to import the idea of research and give us the opportunity to apply and pilot-test in the "health assessment" course, thanks the teachers from health assessment team and students for cooperating with the study. 


\section{References}

[1] Hu T T. The Value of Art in Clinical Medicine_- the Route of Self-perfection and Humanization Service That One Must Take [J]. Medicine \& Philosophy, 2013, 34 (2): 1-3.

[2] Eisner E W. The Arts and the Creation of Mind [J]. Language Arts, 2003, 80 (5): 340-344.

[3] Lake J, Jackson L, Hardman C. A fresh perspective on medical education: the lens of the arts [J]. Medical Education, 2015, 49 (8): 759-772.

[4] Bell L T, Evans D J. Art, anatomy, and medicine: Is there a place for art in medical education? [J]. Anatomical Sciences Education, 2014, 7 (5): 370-378.

[5] Watling C, Driessen E, Vleuten C P M V, et al. Music lessons: revealing medicine's learning culture through a comparison with that of music [J]. Medical Education, 2013, 47 (8): 842850 .

[6] Eisenberg A, Rosenthal S, Schlussel Y R. Medicine as a Performing Art: What We Can Learn About Empathic Communication From Theater Arts. [J]. Academic Medicine Journal of the Association of American Medical Colleges, 2015, 90 (3): 272-276.

[7] Gupta S, Singh S. Confluence: understanding medical humanities through street theatre [J]. Medical Humanities, 2011, 37 (2): 127-128.

[8] Jeffrey E J, Goddard J, Jeffrey D. Performance and palliative care: a drama module for medical students [J]. Medical Humanities, 2012, 38 (2): 110-114.

[9] Shapiro J, Rucker L, Beck J. Training the clinical eye and mind: using the arts to develop medical students' observational and pattern recognition skills [J]. Medical Education, 2006, 40 (3): $263-268$.

[10] Staricoff R L. Arts in health: the value of evaluation [J]. Journal of the Royal Society for the Promotion of Health, 2006, 126 (3): 116-120.

[11] Newell A, Kleiman P. Doctors Can Dance. [J]. London Review of Education, 2012, 10 (2): 133-144.

[12] Karami A, Farokhzadian J, Foroughameri G. Nurses' professional competency and organizational commitment: Is it important for human resource management? [J]. PLoS ONE, 2017, 12 (11): e0187863.

[13] Perry M, Maffulli N, Willson S, et al. The effectiveness of arts-based interventions in medical education: a literature review. [J]. Medical Education, 2011, 45 (2): 141-148.

[14] Fu M Y. The application of whole course training and programmed assessment in practical teaching of health assessment $[\mathrm{J}]$. Contemporary educational practice and teaching research: Electronic Edition, 2017 (6): 140-143.

[15] Xing D J, Sun Y X, Jin X N, et al. Research and Practice on teaching reform of health assessment for nursing students in Higher Vocational Colleges [J]. Health vocational education, 2016, 34 (23): 85-86.

[16] Huang S Y. Research on the performance of music visualization in abstract animation [D]. Beijing Institute Of Fashion Technology, 2018.

[17] Qin X F, Chen J, Guo J, et al. The effects of Visual art training on improving clinical observation ability of nursing master students [J]. Journal of Nursing Science, 2018 (07): 6971.

[18] Bao Y, Liu Y W, Yao D K, et al. Using case study with standardized patients as cases in the clinical observation of cardiac auscultation $[\mathrm{J}]$. China Higher Medical Education, 2017 (1): 1-2

[19] Rong J D, Wang D M, Shi B. The application Diversified Teaching Model in Diagnosis of Cardiopulmonary Auscultation [J]. China Continuing Medical Education, 2017, 9 (18): 28-29.

[20] Pellico L H, Duffy T C, Fennie K P, et al. Looking is not seeing and listening is not hearing: effect of an intervention to enhance auditory skills of graduate-entry nursing students. [J]. Nursing Education Perspectives, 2012, 33 (4): 234-239.

[21] Varpio L, Grassau P, Hall P. Looking and listening for learning in arts-and humanities-based creations [J]. Medical Education, 2017, 51 (2): 136-145.

[22] Meng Y J, Zhao L J, Sun J, et al. Discussion on the teaching methods of undergraduate students in nursing science $[\mathrm{J}]$. Chinese General Practice Nursing, 2014 (12): 1141-1142.

[23] Yang Y. The exploration of the connotation of medical education by art education [J]. Charming China, 2017 (20): 157-157. 